\title{
Über das Verhalten des Pyridins im Organismus des Frosches. Von
}

Kanaé Mayeda und Masajiro Ogata.

(Aus dem medizinisch-chemischen Institut dèr Kaiserlichen Universität zu Kỳoto.)

(Der Redaktion zugegangen am 6. Januar 1914.)

In Übereinstimmung mit der Beobachtung von W. His ${ }^{1}$ ) am Hunde haben Untersuchungen von Z. Hoshiai und G. Totani ${ }^{2}$ ) ergeben, daß nach Verabreichung von. Pyridin an das Huhn, die Ziege und das Schwein Methylpyridylammoniumhydroxyd im Harne auftritt; anderseits ist aber durch Emil Abderhalden und seine Mitarbeiter ${ }^{3}$ ) der Nachweis erbracht worden, daß im Gegensatz zu den obigen Tierarten das Kaninchen nicht Pyridin zu methylieren vermag. Durch diese Arbeiten angeregt, haben wir uns die Frage vorgelegt: welches Verhalten zeigt der Organismus der Kaltblüter dem einverleibten Pyridin gegenüber? Zur Entscheidung dieser Frage waren zuerst einige Versuche an Fröschen angestellt, deren Resultate im Folgenden mitgeteilt werden.

\section{Versuch I.}

7. August 1913، 46 Fröschen wurde zuerst die Haut um den Anus mit einem Faden abgebunden, um den Harn ohne Verlust zu erhalten, und dann je $0,05 \mathrm{~g}$ Pyridin als essigsaures Salz in $10 \%$ i iger Lösung subcutan injiziert. Die Menge des 24 stündigen Harns betrug $331 \mathrm{ccm}$. Der Harn wurde genau nach Angabe von Z. Hoshiai') auf Methylpyridylammonium-

1) W. His, Arch. für exper. Pathol., Bd. 22, S. 253.

2) Z. Hoshiai, Diese Zeitschrift, Bd. 62, S. 118.

Z. Hoshiai u. G. Totani, Diese Zeitschrift, Bd. 68, S. 83.

3) Emil Abderhalden und seine Mitarbeiter, Diese Zeitschrift, Bd. 59, S. 32 u. Bd. 62, S. 133.

4) Z. Hoshiai, a. a. 0 . 
hydroxyd verarbeitet. Es wurden erhalten: 0,0483 g Platinchloriddoppelsalz.

\section{Versuch 2.}

15. August 1913. 46 Frösche wurden auf gleiche Weise wie beim Versuch 1 behandelt und erhielten je 0,05 g Pyridin als essigsaures Salz subcutan eingespritzt. Aus $448 \mathrm{ccm}$ Harn, den die Tiere 24 Stunden nach der Pyridininjektion geliefert hatten, wurden dargestellt: 0,0486 g Platinchloriddoppelsalz.

\section{Versuch 3.}

21. August 1913. 39 Frösche erhielten je 0,05 g Pyridin als essigsaures Salz subcutan injiziert. Sie gaben nach 24 Stunden $379 \mathrm{ccm}$ Harn. Daraus wurden dargestellt: 0,0506 g Platinchloriddoppelsalz.

\section{Versuch 4 .}

1. September 1913. 29 Fröschen wurden je 0,05 g Pyridin als essigsaures Salz subcutan injiziert. Aus $278 \mathrm{ccm}$ des 24 stündigen Harns wurden dargestellt: $0,0360 \mathrm{~g}$ Platinchloridd oppelsalz.

\section{Versuch 5.}

5. September 1913. 45 Frösche erhielten je 0,05 g Pyridin als essigsaures Salz subcutan eingespritzt. Aus $279 \mathrm{ccm}$ des 24 stündigen Harns wurden dargestellt: $0,0573 \mathrm{~g}$ Platinchloriddoppelsalz.

Die einzelnen Portionen des Platinchloriddoppelsalzes wurden vereinigt und durch Umkrystallisation aus heißem Wasser gereinigt. Das so gereinigte Platinchloriddoppelsalz krystallisierte in orangeroten Tafeln und lieferte bei der Analyse die folgenden Werte.

0,2111 g Substanz gaben $0,0690 \mathrm{~g} \mathrm{Pt}=32,69 \% \mathrm{Pt}$.

Berechnet für $\left(\mathrm{C}_{6} \mathrm{H}_{7} \mathrm{NHCl}_{2} \mathrm{PtCl}_{4}\right.$ : Gefunden:

$$
32,74 \% \text {. } 32,69 \% \text {. }
$$

Es unterliegt somit keinem $Z$ weifel, daß das von uns isolierte Platinchloriddoppelsalz identisch mit 
dem Methylpyridylammoniumplatinchlorid ist. Da wir nun durch eigene Versuche haben feststellen können, daß der normale Froschharn keine Spur von Methylpyridylammoniumhydroxyd enthält, und da nach der subcutanen Injektion des Pyridins die genannte Base im Froschharne ausgeschieden wird, so glauben wir uns zum Schluß berechtigt, daß der Organismus des Frosches befähigt ist, die Methylierung des zugeführten Pyridins auszuführen.

\section{Zur Frage der Anomalie der Harnsäurelöslichkeit (kolloide Harnsäure). \\ Von \\ F. Gudzent.}

(Der Redaktion zugegangen am 16. Dezember 1913.)

Schade und Boden () haben in dieser Zeitschrift unter obigem Titel eine Arbeit veröffentlicht, in der sie die Möglichkeit des Vorkommens einer intermediären Kolloidform der Harnsäure im Blut bewiesen zu haben glauben. Lichtwitz ${ }^{2}$ ) hat alsbald auf eine Reihe Widersprüche und vor allem darauf hingewiesen, daß keinesfalls der Beweis für eine kolloidale Zwischenform in wässerigen Lösungen erbracht ist, und der Schluß über die Möglichkeit dieses Vorkommens im Serum darum hinfällig wird. Die Entgegnung von Schade und Boden ${ }^{3}$ ) vermag diese Hinweise von Lichtwitz nicht überwiegend zu widerlegen. Inzwischen hat nun auch Kohler ${ }^{4}$ ) durch einwandfreie experimentelle Nachprüfung dargetan, daß eine kolloide Form der Harnsäure im Sinne von Schade und Boden nicht existiert.

Gelegentlich anderer Studien konnte ich nun eine Beobachtung machen, die ebenfalls gegen die Annahme von Schade und Boden spricht.

Die Ultrafiltration gestattet bekanntlich unter gewissen Voraussetzungen, die Kolloide von ihrem Lösungsmittel zu trennen.

2) Bd. 83, H. 5 .

2) Diese Zeitschrift, Bd. 84, H. 6.

3) Diese Zeitschrift, Bd. 86, H. 3.

4) Zeitschrift f. klin. Medizin, Bd. 78, H. 3 und 4. 